\title{
Estrutura e funcionamento de uma equipe de saúde mental de Trieste na perspectiva de seus integrantes: um estudo qualitativo
}

Structure and functioning of a mental health team of Trieste in its members perspective: a qualitative study

\author{
Thaís Thomé Seni da Silva e Oliveira ${ }^{\mathrm{I}}$ \\ Departamento de Saúde Mental de Trieste, Itália
}

Elisabetta Pascolo Fabrici ${ }^{\text {II }}$

Università degli Studi di Trieste, Itália

Manoel Antônio dos Santos ${ }^{\text {III }}$

Universidade de São Paulo

\section{Resumo}

O Modelo de Atenção Psicossocial vigente no Brasil requer práticas interdisciplinares e intersetoriais que produzam autonomia e cidadania. Esse modelo teve forte inspiração no modelo italiano. Este estudo teve por objetivo investigar a estrutura e funcionamento de uma equipe de saúde mental de Trieste, Itália, referência internacional na área, na perspectiva de seus integrantes. Entrevistas semiestruturadas foram realizadas com nove profissionais. As entrevistas audiogravadas foram transcritas e analisadas qualitativamente. Os resultados apontam que a cobertura populacional do serviço, número de profissionais, organização das práticas, frequência e qualidade de reuniôes são recursos essenciais. O eixo central do trabalho é a existência de múltiplos espaços de discussão para a equipe e usuários, que potencializam práticas centradas na pessoa e no território. O processo de reflexão contínua é pautado em açôes não-especialísticas e na discussão sobre as práticas cotidianas.

Palavras-chave: saúde mental; equipe interdisciplinar; profissionais da saúde; centros comunitários de saúde mental; atenção psicossocial.

\section{Abstract}

The Psychosocial Care Model, public policy on mental health in Brazil requires interdisciplinary and intersectoral practices producing autonomy and citizenship. This model had strong inspiration in the Italian model. This study aimed to investigate the structure and functioning of a mental health team of Trieste, Italy, whose network services is considered an international reference. Semi-structured interviews were conducted with nine professionals. The audio-recorded interviews were transcribed and qualitatively analyzed. Results pointed out that the population coverage of the service, number of professionals, territorial and service actions organization, frequency and quality of the meetings are essential resources. The central axis of the work is the existence of multiple discussion spaces for staff and users, which enhance practices centered on the person and in the territory. The process of continuous reflection is based on non-specialistic actions and the discussion about everyday practices.

Keywords: mental health; interdisciplinary team; health professionals; community mental health centers; psychosocial care.

Poucos são os campos de conhecimento e atuação em saúde tão complexos, plurais e intersetoriais como a saúde mental (Amarante, 2008). Esse campo, como toda área de conhecimento, possui uma história. Tal percurso histórico engloba transformaçóes que passam por concepçôes naturalistas, mágico-religiosas, pelo modelo dualista-racionalista da psiquiatria tradicional e, atualmente, se aproxima do chamado modelo de atenção psicossocial.

Foucault (2000) considera que as práticas sociais e médicas são inseparáveis do discurso que as instaura. Nessa direção, pode-se afirmar que as formas contemporâneas de cuidado resultam de um processo sócio-histórico e cultural que envolve transformaçôes no

\footnotetext{
I Thaís Thomé Seni da Silva e Oliveira: Psicóloga, Mestre, Doutora e Pós-doutora pela Universidade de São Paulo Pesquisadora colaboradora do Departamento de Saúde Mental de Trieste, Dipartimento di Salute Mentale di Trieste, Itália.

II Professore aggregato e ricercatore per l'area scientifico disciplinare MED/25 Psichiatria, in servizio pressola Facoltà di Medicina e Chirurgia dell'Università degli Studi di Trieste e Direttore di Struttura Complessa dell'A.S.S. n. 1 Triestina, Itália.

III Professor Titular do Departamento de Psicologia da Faculdade de Filosofia, Ciências e Letras de Ribeirão Preto da Universidade de São Paulo, Ribeirão Preto, SP, Brasil. Coordenador do Laboratório de Ensino e Pesquisa em Psicologia da Saúde (LEPPS-USP-CNPq). Bolsista de Produtividade em Pesquisa do CNPq, nível 1B. Membro Titular da Academia Paulista de Psicologia, cadeira 33.
} 
que se refere aos conceitos e às práticas desenvolvidas ao longo do tempo e em diferentes contextos sociais.

Franco Basaglia, psiquiatra italiano, iniciou no início da década de 1970 um movimento que almejava a abolição do manicômio, da segregação e da discriminação imposta ao louco. Esse movimento se inspirava em outros movimentos que, ao longo da década anterior, buscavam reposicionar as estratégias de tratamento preconizadas pela psiquiatria tradicional e, especialmente, superar o modelo hospitalocêntrico de atenção em saúde mental. Esses movimentos de vanguarda na época instauraram rupturas substanciais com os modelos de atenção precedentes, que buscavam reformar o hospital psiquiátrico (Amarante, 1995).

O movimento deflagrado por Basaglia em Trieste, Itália, culminou com a publicação da Lei 180, em 1978. Esse dispositivo legal propõe a supressão das longas internações hospitalares, a desmontagem do aparato manicomial mediante a construção de novos espaços de atenção inseridos na cidade e novas estratégias de cuidado em saúde mental (Del Giudice, 1998). O novo modelo institui como marca distintiva a preocupação com a desinstitucionalização e o acesso à cidadania. Por isso, de acordo com Mezzina (2017), a legislação de 1978 é baseada na garantia de direitos aos usuários dos serviços, como a questáo dos tratamentos obrigatórios, a livre comunicação, o direito de recurso, a impossibilidade de manter o paciente segregado do convívio social por períodos prolongados e a ausência de detenção. Como resultado da nova política de saúde mental, ao longo do tempo a reforma psiquiátrica italiana promoveu a menor taxa de tratamento obrigatório dentre os países da Europa e a menor duraçáo média de internação, evitando as chamadas "carreiras institucionais" que caracterizavam a trajetória dos usuários dos serviços de saúde mental.

\section{Novos ventos chegam aos trópicos: a Reforma Psiquiátrica brasileira}

A bem-sucedida experiência italiana deu impulso a um movimento que influenciou de modo marcante a chamada "reforma psiquiátrica" no Brasil (Amarante, 2011; Yasui, 2011). No cenário nacional, a transformação na atenção dirigida ao "louco" tem semelhanças e peculiaridades em relação ao que se observou no contexto internacional.

Para compreender a real dimensão dessa influência é preciso recuar no tempo. Nos primórdios, a experiência brasileira foi marcada pela instalação de colônias agrícolas, pela consolidação da estrutura asilar ao longo da década de 1930 e pelo advento da psiquiatria comunitária entre as décadas de 1960 e 1970 (Pegoraro, 2007; Resende, 1990).

Kantorski (2001) assinala que o modelo hospitalocêntrico se expandiu no Brasil por ter recebido um impulso decisivo durante o processo de industrialização que marcou os anos 1970, década do chamado "milagre econômico" deflagrado pelo regime militar, que governava autoritariamente o país naquela quadra histórica. Nesse período ocorreu uma notável expansão da indústria farmacêutica e de equipamentos médico-hospitalares. De fato, como destaca a autora, enquanto o mundo voltava-se para a desospitalização, o Brasil, sob o cenário da ditadura de direita que se instalara em 1964, transitava na contramão e investia na extensáo dos cuidados psiquiátricos tradicionais por meio do aumento do número de leitos hospitalares e da multiplicação da rede privada de assistência psiquiátrica. A loucura era tratada como um problema eminentemente médico-psiquiátrico e o tratamento preconizado era exclusivamente hospitalar, o que acabaria revertendo em grandes margens de lucro para os donos de hospitais psiquiátricos particulares.

No final da década de 1970, iniciou-se um movimento sintonizado com a luta pela redemocratização do país, fruto da resistência da sociedade civil contra a perenizaçáo no poder do regime ditatorial sustentado pelos militares golpistas que tomaram o poder. Esse movimento de resistência pacífica articulava ações que estimulavam o debate público sobre os caminhos e descaminhos da assistência em saúde mental no país. Foi uma época marcada por contestaçôes à ordem vigente, com mobilizaçóes orquestradas pelos setores organizados da sociedade civil, como o Movimento dos Trabalhadores em Saúde Mental (MTSM), que reivindicavam o retorno ao regime democrático e ao Estado Pleno de Direito. Nesse contexto de intensa efervescência social floresceram as condiçóes objetivas para a instalação de ideias inovadoras, que se refletiram na busca de transformaçôes estruturais no modelo de atençáo em saúde mental então praticado. Assim nasceu a denominada "luta antimanicomial", movimento fortemente inspirado na experiência italiana (Machado \& Santos, 2012)

Por meio do MTSM várias denúncias sobre o tratamento oferecido aos chamados "doentes mentais" chegaram ao conhecimento da sociedade, evidenciando a existência de práticas opressivas semelhantes às dispensadas aos presos políticos pelos representantes da ditadura militar, ou que, em uma perspectiva histórica, remetiam à barbárie praticada nos campos de concentração nazistas durante a Segunda Guerra Mundial. A indignaçáo 
crescente frente às formas desumanas de tratamento estimulou a criação de projetos de reforma na assistência psiquiátrica no setor público brasileiro (Amarante, 1995).

Em 2001, após anos de tramitação no Congresso Nacional e de intensa mobilização de forças progressistas do espectro social brasileiro, finalmente foi aprovada a Lei 10.216, que ficaria mais conhecida como lei da Reforma Psiquiátrica, que estabeleceu os direitos das pessoas com transtornos mentais e redirecionou a assistência psiquiátrica no país, preconizando a criação de uma rede de serviços substitutiva ao hospital psiquiátrico que até então era o centro da atenção em saúde mental (Machado \& Santos, 2013a). A rede de atenção extra-hospitalar ainda vem sendo implementada nos dias de hoje e de forma bastante heterogênea nas diversas regióes do país (Ministério da Saúde, 2015).

Atualmente, as políticas em saúde mental do Estado brasileiro se caracterizam por açóes integradas dos governos federal, estadual, municipal e de movimentos sociais, que buscam efetivar a pretendida transição do modelo centrado no hospital psiquiátrico para um modelo de atenção comunitário e baseado na comunidade (Machado, Leonidas, \& Santos, 2012). Esse novo modelo é chamado Atenção Psicossocial (Amarante, 2011; Costa-Rosa, 2000) ou Estratégia Atenção Psicossocial (Costa-Rosa, 2013; Yasui \& CostaRosa, 2008), que não se restringe à disponibilização de uma rede de serviços que se propóem a substituir o manicômio, mas representa a instauração de um outro paradigma de cuidado em saúde mental, que acompanha a mudança paradigmática implantada em diversos países e continentes envolvendo desde a problematização do conceito de saúde mental até as táticas de tratamento e as estratégias de cuidado (Yasui, 2010). Assim, no cenário internacional, fala-se de uma transição paradigmática em termos semelhantes, com os termos mais comuns na literatura, que partem do denominado biological-medical model em direção ao modelo de psychossocial approaches (Mezzina, 2005; OliveiraPereira, Barros, \& Augusto, 2011; Romeo, 2010).

Nos últimos anos, houve um significativo aumento no número de dispositivos de atenção extra-hospitalar (Ministério da Saúde, 2015), o que, segundo Mari et al. (2006), é uma evidência positiva em termos de investimentos na área. Porém, os autores apontam a necessidade de avaliação dos serviços e a preocupaçáo com a qualificação dos profissionais que neles atuam, além da continuidade da expansão da rede, necessária para a consolidação dessa política de assistência.

Nessa direção, considera-se que a qualificação dos profissionais de saúde, em suas diversas modalidades e categorias profissionais, é uma peça-chave para o adequado funcionamento da rede no modo de atenção psicossocial (Machado \& Santos, 2013a, 2013b). Destaca-se, ainda, que o adequado preparo técnico do profissional envolve o modo como o trabalho nas equipes interdisciplinares tem se processado no cotidiano dos serviços.

\section{A equipe interdisciplinar de saúde mental}

Mezzina (2005) aponta que, quando a comunidade passa a ser vista como o novo cenário da produção do cuidado em saúde mental, coloca-se o desafio de construir práticas que, de fato, sejam substitutivas às consagradas tradicionalmente pelas instituiçóes totais. Segundo o autor, para se ter serviços comunitários realmente inovadores se faz necessário evitar os riscos de produzir uma nova instituição difusa, que reproduza práticas baseadas no controle de sintomas, na fragmentação do sujeito e na distância calculada entre profissionais e pacientes, o que acabaria por produzir, à maneira do que ocorre no paradigma biomédico, instituiçôes fragmentadas e manicômios difusos. Assim, as práticas devem se construir a partir da articulação de diferentes áreas profissionais, disciplinas e saberes que possam dar conta da totalidade da pessoa, evidenciando a essencialidade do trabalho em equipes interdisciplinares. De fato, o trabalho interdisciplinar é uma das premissas estabelecidas pela Organização Mundial de Saúde (OMS) para a área da saúde mental (Campos-Brustelo, Bravo, \& Santos, 2010; World Health Organization, 2005)

Romeo (2010) considera que uma equipe verdadeiramente interdisciplinar deve ter, além dos objetivos comuns, a colaboração de todos os seus membros no planejamento e na realização de tratamentos e cuidados, além da partilha nos processos de tomada de decisóes. $\mathrm{O}$ autor ressalta que um bom funcionamento da equipe, com boa comunicação e interação entre seus membros, é quase sempre garantia de êxito.

Segundo Vasconcellos (2010), a literatura especializada buscou nos últimos anos caracterizar os pontos críticos para a integração interdisciplinar em saúde. São eles: o poder da tradição positivista e biocêntrica, ausência/presença de um projeto comum, o confronto entre especificidade e flexibilização na realização do trabalho, a comunicação e existência de concepçóes de integralidade imprecisas e/ou equivocadas entre os profissionais de saúde. No que se refere especificamente às equipes de saúde mental de Trieste, berço do movimento de desinstitucionalização capitaneado por Basaglia, o trabalho em equipe se materializa por meio da formulação coletiva 
de projetos terapêuticos, da coordenação entre as várias figuras profissionais, de abordagens interdisciplinares, do investimento na formação contínua em serviço e de açóes compartilhadas pela equipe, da circulação da informação dentro dos serviços e integração de trabalho não profissional, como é o caso dos peer supporters (Mezzina, 2014).

Porém, não existem pesquisas específicas sobre a estrutura e funcionamento dos serviços, o que confere ao presente trabalho um caráter original e inovador.

Para se iniciar o processo de reflexáo e compreensão sobre a atuação das equipes dos serviços de saúde mental triestinos, é importante compreender a base conceitual e as diretrizes programáticas desse trabalho, que informam e direcionam suas práticas cotidianas. É preciso ter clareza de que o objeto de trabalho dos operadores da saúde mental não é mais a doença, mas a existência sofredora do sujeito inserido em seu contexto social (Del Giudice, 1998; Rotelli, 1990). A periculosidade social não é mais relacionada à doença, mas é entendida em relação aos contextos em que a vida acontece e à ausência de resposta efetiva dos serviços de saúde. A cronicidade não é mais vista como um atributo imprescindível do indivíduo com diagnóstico de transtorno mental, mas um artefato histórico fortemente relacionado à (in)operatividade dos serviços e à ordem simbólica da internação, considerando inclusive o lado iatrogênico da hospitalização. Nas práticas de saúde mental inspiradas no modo de atenção psicossocial cada vez mais se valoriza a diversidade e se promovem conexões e intercâmbios com a comunidade, com vistas à potencialização de estratégias de cuidado que acolham ou instaurem novas possibilidades de existir.

Considerando os pressupostos apresentados, este estudo teve por objetivo investigar a estrutura e funcionamento de uma equipe de saúde mental de Trieste, Itália, na perspectiva de seus integrantes. Considera-se que conhecer e compreender na atualidade a estrutura e funcionamento da rede de serviços em saúde mental de um centro de referência internacional pode contribuir com elementos instigadores de reflexão acerca dos serviços de saúde mental no Brasil e, assim, fornecer subsídios para o aperfeiçoamento da assistência e o planejamento de políticas públicas de saúde.

\section{MÉTODO}

\section{Percurso metodológico}

Este estudo se insere na tradição das abordagens qualitativas de pesquisa (Bogdan \& Biklen, 1994). A pesquisa qualitativa busca a compreensão dos fenômenos em detrimento de sua explicação causal. Nessa perspectiva, Bogdan e Biklen definem como características da investigação qualitativa: o ambiente natural como fonte direta de dados, o investigador como o instrumento principal da pesquisa, o caráter descritivo da investigação qualitativa, o interesse maior no processo do que no resultado obtido, a forma indutiva de analisar os dados e, finalmente, a importância vital da construção de significados e o interesse pela subjetividade, ressaltando o modo pelo qual diferentes indivíduos ou grupos significam experiências e estruturam o mundo social em que vivem.

\section{Cenário do estudo}

O presente estudo foi realizado em um dos serviços do Departamento de Saúde Mental de Trieste. Tal departamento organiza a rede de cuidados em saúde mental no contexto local e regional. A escolha dessa instituição como cenário de investigação das práticas em saúde mental se justifica devido às parcerias colaborativas estabelecidas pelo Departamento com diversos países, principalmente com universidades e centros de pesquisa ao redor do mundo, visando ao aprimoramento das atividades de ensino e pesquisa no campo psicossocial. Por esse motivo o Departamento de Saúde Mental de Trieste é reconhecido pela OMS como Centro Colaborador para Pesquisa e Treinamento em Saúde Mental (World Health Organization, 2010).

O Departamento de Saúde Mental de Trieste opera sem manicômio há 45 anos, funcionando com um sistema de portas abertas. O fluxograma de assistência do Serviço Sanitário Regional inclui a oferta de Centros de Saúde Mental abertos em regime integral de 24 horas com seis leitos cada. Outros recursos de apoio disponibilizados são: um sistema de habitação e uma pequena unidade de retaguarda em hospital geral, que oferece seis leitos (Mezzina, 2017). Trata-se de uma rede composta pelos seguintes serviços articulados entre si (Servizio Sanitario Regionale, 2012):

- Quatro Centros de Saúde Mental (CSM): ativos 24 horas, servem a uma populaçáo de cerca de 60.000 habitantes. Cada centro conta com leitos para permanência breve, em áreas coincidentes com cada distrito de saúde da cidade.

- Clinica Psiquiátrica da Universidade de Trieste, que mantém parceria com o Departamento de Saúde Mental e responde à área de San Giovanni (Distrito 4, com 12.000 residentes), com açóes territoriais próximas às utilizadas no contexto do quadro. 
- Serviço de Habilitação e Residências (SAR), que coordena e promove atividades residenciais, atividades de formação e colocação profissional, em colaboração com o sistema de serviços departamentais, com cooperativas sociais, associaçôes credenciadas e voluntárias.

- Serviço Psiquiátrico de Diagnóstico e Cura (SPDC), com leitos localizados no Hospital Geral (Ospedale Maggiore di Trieste); esse serviço atua como uma resposta para a coordenação de urgência e emergência.

\section{Participantes}

A amostra intencional foi composta por nove profissionais. Seis participantes eram integrantes da equipe interdisciplinar do Centro di Salute Mentale della Maddalena - um dos quatro Centros de Saúde Mental de Trieste, Itália. Três eram profissionais de outros Centros de Saúde Mental, que também pertencem à rede triestina; estes centros não serão destacados para evitar uma possível identificação dos participantes.

Em relação ao sexo, sete participantes eram homens e duas mulheres. As idades variaram de 26 a 59 anos. No que concerne às especialidades, três profissionais eram enfermeiros (sendo duas mulheres e um homem), dois psicólogos, um estagiário de Psicologia, um médico psiquiatra, um residente em Psiquiatria e um assistente social. O tempo de atuação no Departamento de Saúde Mental variou de 38 anos (médico psiquiatra) a seis meses (estagiário de Psicologia). Seis profissionais haviam cursado especialização ou residência em suas respectivas áreas.

\section{Instrumentos}

\section{Roteiro de entrevista semiestruturada}

Após um período de acompanhamento da equipe em suas atividades cotidianas, foram realizadas entrevistas individuais com os participantes, baseadas em um roteiro de entrevista semiestruturada. Optou-se pela modalidade de entrevista semiestruturada porque nela o entrevistado não tem de se adaptar a um roteiro rígido de questóes, mas encontra ampla liberdade de expressar seu pensamento da maneira que lhe parecer mais conveniente e confortável. Nessa modalidade de entrevista a pessoa entrevistada pode inclusive explorar aspectos para os quais não foi dada a devida atençáo pelo pesquisador, o que permite a captura de uma riqueza maior de informaçôes (Bogdan \& Biklen, 1994).

\section{Caderneta de campo}

Contém o registro das observaçóes resultantes da experiência de imersão da pesquisadora no campo de pesquisa. Inclui o acompanhamento de atividades desenvolvidas pela equipe do serviço pesquisado, tais como: intervençóes realizadas pelos profissionais da equipe no serviço e no território, visitas domiciliares e reunióes da equipe interdisciplinar.

\section{Procedimento}

\section{Coleta de dados}

A coleta de dados foi realizada no primeiro semestre de 2015, na cidade de Trieste, Itália. Em um primeiro momento, a pesquisadora realizou uma imersão no contexto pesquisado, acompanhando algumas atividades realizadas pela equipe, tais como reunióes e atividades desenvolvidas nos serviços e no território.

As entrevistas foram realizadas mediante anuência do profissional ao convite para participar da pesquisa. Três profissionais consultados se recusaram a colaborar, sendo que um deles havia assumido a função há poucos meses e os outros estavam em processo de transferência para outro serviço sanitário. Três profissionais de outros centros de saúde mental foram contatados e, depois de informados sobre os objetivos do estudo, prontificaram-se a participar.

As atividades acompanhadas durante a imersão no campo foram registradas em caderneta de campo. As entrevistas individuais realizadas com os participantes foram audiogravadas e, posteriormente, transcritas na íntegra. $\mathrm{O}$ material foi organizado de modo a favorecer a análise de seu conteúdo.

A partir de uma inspeção preliminar dos dados obtidos, foi realizada uma devolutiva dos resultados à equipe pesquisada. A devolutiva consistiu em uma apresentação oral dos resultados realizada pela pesquisadora, com auxílio de recursos audiovisuais, seguida de discussão com os profissionais da equipe presentes. Essa etapa é considerada por Turato (2003) como importante em um estudo clínico-qualitativo, pois permite a validação dos resultados da pesquisa por parte dos seus participantes.

\section{Análise dos dados}

O material de análise consiste no corpus constituído pelas transcriçóes das entrevistas semiestruturadas com os participantes e nas anotaçóes da caderneta 
de campo realizadas durante a imersão no campo de pesquisa. $\mathrm{O}$ corpus da pesquisa foi submetido à análise temática, de acordo com os passos metodológicos preconizados pela literatura: leitura exaustiva, identificação de temas, extração de categorias e redação do relatório final (Braun \& Clark, 2006).

\section{Cuidados éticos}

É importante ressaltar que o Brasil conta com uma legislação específica sobre pesquisas que envolvem seres humanos. Todos os cuidados éticos foram tomados, visando atender aos princípios contidos na Resolução 466/2012 do Conselho Nacional de Saúde e a Resolução 16/2000 do Conselho Federal de Psicologia. Porém, o projeto não foi submetido a um comitê de ética em pesquisa brasileiro em função da coleta de dados ter sido realizada em país estrangeiro. A Resolução 466/2012 do Conselho Nacional de Saúde determina que os procedimentos éticos e determina que a submissáo do projeto de pesquisa aos Comitês de Ética em Pesquisa tem validade apenas para pesquisas realizadas com participantes brasileiros e em território nacional.

Sendo assim, foram seguidas as instruçóes contidas na normativa brasileira e adotamos os procedimentos éticos vigentes na Itália para pesquisas envolvendo seres humanos, que consistem na aprovação do projeto e dos procedimentos de investigação pelo supervisor colaborador, que é pesquisador de uma universidade italiana, e pelo Departamento de Saúde Mental de Trieste, que ofereceu o campo de pesquisa.

\section{RESULTADOS E DISCUSSÃO}

Tendo em vista os objetivos do presente estudo, a análise dos resultados permitiu delinear três categorias centrais, denominadas: Aspectos estruturais das equipes dos Centros de Saúde Mental, Aspectos funcionais e dinâmicos do Departamento de Saúde Mental de Trieste e Funcionamento da equipe na visáo de seus integrantes.

\section{Aspectos estruturais das equipes dos Centros de Saúde Mental de Trieste}

Os dados apresentados a seguir resultam da sistematização dos registros de campo, elaborados durante o acompanhamento das atividades da equipe investigada e se referem aos aspectos estruturais do trabalho realizado pelas equipes triestinas. As equipes dos quatro Centros de Saúde Mental de Trieste têm, aproximadamente, a mesma composição, cada uma contando com 40 profissionais em média.

No Centro de Saúde Mental pesquisado a equipe é composta por 12 enfermeiros, quatro médicos psiquiatras (incluindo o coordenador do serviço) e dois residentes de Psiquiatria, duas assistentes sociais, dois psicólogos e um estagiário de Psicologia, seis operadores sócio-sanitários (operatori sociosanitari, profissionais de nível técnico) e dois técnicos de reabilitação psicossocial, especialidade que também não tem similaridade no Brasil e que na Itália exige formação técnica específica.

Cada Centro de Saúde Mental é coordenado por um médico psiquiatra e conta também com uma coordenaçáo para a área de Enfermagem (enfermeiros e operadores sócio-sanitários) que organiza os turnos de trabalho. A maioria dos profissionais trabalha 38 horas por semana, sete horas e 12 minutos por dia. Dezoito profissionais (enfermeiros e operadores sócio-sanitários) atuam em turnos de 12 horas. Outro aspecto estrutural importante de ser mencionado é que cada centro de saúde mental de Trieste possui ao menos quatro carros à disposição dos profissionais da equipe para realizar as intervençôes no território.

Com a descrição dos aspectos estruturais iniciam-se as reflexốes sobre a importância de considerar os aspectos quantitativos e qualitativos da organização do trabalho em saúde mental, como o número de profissionais da equipe, a amplitude de cobertura populacional dos serviços, características que serão discutidas na sequência, bem como a disponibilidade de veículos em boas condiçóes de uso nas estruturas sanitárias para que a equipe possa se deslocar e realizar o trabalho no território.

\section{Aspectos funcionais e dinâmicos do Departamento de Saúde Mental de Trieste}

As equipes dos quatro centros de saúde mental de Trieste mantêm a mesma rotina de funcionamento. Os profissionais se reúnem cotidianamente duas vezes ao dia. A primeira reunião ocorre no início da manhã e tem um caráter organizador das atividades do dia. Em um grande diário-agenda do serviço são registradas todas as atividades externas que serão realizadas e por quais operadores: visitas domiciliares, açóes no território e acolhimento de casos novos. Cada reunião tem duração média de uma hora e ocorre de segunda a sexta-feira.

A segunda reuniáo acontece no início da tarde e abrange todos os profissionais da equipe presentes no serviço, incluindo aqueles que estão em regime de turno. Nessa reunião acontece a discussão dos casos que 
se encontram em atendimento e também dos novos, especialmente aqueles de alta complexidade. Todos os profissionais da equipe devem ter conhecimento de todos os casos. Essa reunião dura, em média, uma hora e meia, e também ocorre de segunda a sexta-feira.

Cada profissional é referência para 10 casos e cada usuário conta com dois profissionais de referência da equipe. É importante destacar que a valorização dos espaços de discussão é uma marca da organização do trabalho em Trieste. O funcionamento de cada serviço é balizado pela realização dessas duas reuniôes de equipe diárias, que proporcionam o compartilhamento de informaçôes sobre os usuários atendidos, favorecendo a tomada de decisóes e a interlocução.

Conforme Mezzina (2014), ao reconhecer a relação circular existente entre serviço, práticas e concepções que sustentam essas açôes, Trieste investe constantemente em treinamento, motivação e desenvolvimento da equipe, mediante o fortalecimento dessas reuniōes diárias em cada serviço. Dessa maneira, os momentos de encontro da equipe fazem parte da organização do trabalho cotidiano e instrumentalizam os profissionais para a promoverem açóes que consideram a pessoa e seu contexto de vida, tomando-a em sua totalidade e singularidade.

Transpondo essas reflexóes para o contexto brasileiro, a partir do estudo realizado, constata-se que a frequência e qualidade dos encontros da equipe estão diretamente relacionadas aos aspectos estruturais anteriormente referidos, ou seja, à maneira como está configurada a rede de serviços no país, à distribuição proporcional de serviços no território - que no caso de Trieste é da ordem de um centro de saúde mental para cada 60.000 habitantes $^{1}$, ao número de profissionais da equipe e à participação de todos, inclusive dos médicos, nas reuniōes.

No Brasil, no que se refere à cobertura da rede assistencial em saúde mental, as diretrizes ministeriais estabelecem uma meta em relação aos centros de saúde mental. O Centro de Atenção Psicossocial - CAPS é planejado e dimensionado para cada 100 mil habitantes (Ministério da Saúde, 2005). O relatório do Ministério da Saúde (2015) aponta um crescimento da rede de atenção psicossocial em todo o território nacional,

1 Conforme descrito anteriormente, de modo diverso da realidade brasileira, a estrutura de serviços sanitários da Itália conta com departamentos distintos para a saúde mental - Departamentos de Saúde Mental - e para os problemas relacionados ao uso de substâncias - Departamentos de Dependência, o que implica em duas redes de serviços, que são diversas e complementares, como também em linhas de financiamento diferentes (Servizio Sanitario Regionale, 2012). graças à criação de novos CAPS em todas as regiôes do país, apresentando atualmente um índice de 0,61 (região Norte) a 1,0 (Região Nordeste) na proporção 1/100.000 habitantes.

Porém, além de o desenvolvimento da rede de serviços ser bastante heterogêneo nas diferentes regióes e municípios, os dados apresentados incluem todos os tipos de CAPS, ou seja, CAPS I, II e III, CAPSad e CAPSi, que atendem públicos diferentes (adultos com transtornos mentais severos ou moderados, adultos que fazem uso de álcool e/ou de outras drogas - CAPSad - e crianças e adolescentes - CAPSi), sendo que apenas o CAPS III tem funcionamento em regime de 24 horas. Essa realidade convida a refletir sobre a relação entre proporcionalidade, demanda e produção de boas práticas na rede de serviços de saúde mental.

Saraceno (2014), em sua análise dos movimentos de saúde mental em diversos países do mundo, aponta que existem três barreiras ao desenvolvimento de serviços sanitários inovadores:

- A ausência ou insuficiência de vontade política de transformação por parte dos governos nacionais, devido à desinformação, preconceitos ou interesses econômicos. A principal consequência é a escassez e insuficiência de investimentos financeiros, infraestruturais e humanos, como também a falta de legislação específica e de políticas de saúde mental efetivas;

- A inadequação ética e/ou técnica das políticas de saúde mental e, portanto, da organização dos serviços, causada pela pouca preparação cultural e técnica dos administradores sanitários locais e dos próprios técnicos;

- Oposição à transformação e aprimoramento dos serviços por parte de famílias e associaçóes familiares, motivada pelo caráter estigmatizante reforçado pela psiquiatria e pela baixa resolutividade das açôes implementadas, decorrente dos motivos anteriormente referidos.

É importante mencionar que Saraceno (2014), em sua análise global dos movimentos e reformas psiquiátricas, aponta o Brasil como um país estrategicamente importante por sua vasta dimensão territorial, e que há mais de duas décadas persegue uma corajosa reforma do sistema de saúde mental:

O Brasil soube em parte superar a barreira representada pela insuficiência e ineficácia dos investimentos financeiros, de infraestrutura e de recursos humanos, e viu nascer e se desenvolver um robusto movimento pela renovação dos serviços públicos que envolvem técnicos, familiares, usuários e sociedade civil (Saraceno, 2014, p. 70).

Vale ressaltar que o Brasil é o maior país do mundo, em extensão territorial, a adotar um sistema 
de saúde público e com abrangência e cobertura universal, incluindo uma rede de atenção comunitária à saúde mental. Essa proeza encerra um desafio e ao mesmo tempo um convite à reflexão, no sentido de que impóe pensar em formas de dar continuidade ao movimento de transformação empreendido não só para que se possa ampliar a rede existente, mas também - e sobretudo consolidar os avanços alcançados, de modo a assegurar o fluxo de investimento de recursos, evitando retrocessos nas políticas públicas.

\section{Funcionamento da equipe na visäo de seus integrantes}

A partir dos relatos transcritos das entrevistas realizadas com os participantes do estudo, foi construído o eixo temático referente às concepçóes dos profissionais sobre o funcionamento da equipe da qual fazem parte. $\mathrm{O}$ trabalho em equipe coloca em ato uma série de estratégias de ação que necessitam ser coordenadas, de onde se depreende sua complexidade. No modelo de Atenção Psicossocial a pessoa em sua totalidade ocupa o centro das práticas de cuidado em saúde mental (Machado \& Santos, 2012; 2013b).

. O usuário não é apenas o destinatário das ações, mas sua razão de ser, a dimensão que dá sentido às intervençóes construídas com os profissionais.

De acordo com os participantes, a interdisciplinaridade acontece em três níveis:

1. No momento da intervenção propriamente dita, quando se está em contato com a pessoa no trabalho territorial;

2. Na discussão que se realiza durante as reuniōes, nas quais se deve estar atento à linguagem utilizada e às relaçôes de poder que estão em jogo nas açóes implementadas;

3. Em um último nível, que se refere à representação do trabalho dos operadores, ou seja, as concepçóes que circulam entre os próprios operadores e também as que são elaboradas pelos gestores.

Os participantes expressam uma representação bastante positiva acerca da equipe e da interdisciplinaridade. Referem-se a uma desejável homogeneidade de papéis e a um questionamento contínuo e positivo das relações de poder e das contradiçóes engendradas pela efetivação das próprias ações. Nessa concepção, as ações específicas desenvolvidas por cada área são consideradas de importância secundária, conforme se pode depreender dos excertos de fala selecionados:

Sobre as especialidades profissionais, eu na realidade não coloco tanta ênfase. Não enfatizo tanto esse aspecto, a reivindicação da especificidade profissional eu acho uma questão pouco interessante. Eu acho a formação profissional importante. De fato, ter diversos paradigmas e visóes ontológicas do mundo é importante, mas depois eu sempre vejo que os projetos, o trabalho sobre as pessoas, com as pessoas, se faz entre pessoas, não entre profissionais. Eu trabalho bem se consigo instaurar açôes positivas em nível subjetivo e pessoal, se consigo achar um objetivo em comum. Tem alguns que demarcam sempre essa questão das áreas profissionais, mas se trabalhar nesses serviços nos ensinou alguma coisa, foi também fazer cair a máscara das especificidades profissionais (assistente social).

As figuras são muito homogêneas, não é uma coisa "especialística”. Os objetivos são os mesmos, que é a pessoa e tudo o que se refere a ela. O que facilita é a comunicação e o compartilhamento da operatividade. A comunicação acontece, há muito para se trabalhar, sempre tem... Esse aspecto poderia ser melhor desenvolvido na codivisão das dificuldades e na clarificação do modelo operativo (enfermeiro).

O conhecimento médico evoluiu para uma crescente busca da especialização, a ponto de essa se tornar a marca da formação profissional dentro de um paradigma tecnocientífico nas últimas décadas (Schraiber, 1993, 2008). Na atualidade, o paradigma da interdisciplinaridade tenta quebrar essa visão que organiza o trabalho em saúde como uma mera justaposição de especialidades, na qual cada disciplina profissional tem suas fronteiras asseguradas por meio de ações exclusivas que supostamente garantiriam a identidade de cada área de atuação. No campo da saúde mental, a especificidade favorece uma visão recortada da pessoa, que é concebida como a mera soma das partes que a constituem (Fiorati \& Saeki, 2013; Mângia, 2009) ou reduzida a uma representação unidimensional, seja ela biológica, psicológica ou social.

Os entrevistados deste estudo sustentam uma concepção bem diferente dessa representação reducionista da vida e do humano. Mostram-se seguros de suas convicçóes e tem um claro entendimento do seu próprio lugar e papel social. Compreendem que a autonomia 
profissional, que caracteriza a concepção liberal da organização do trabalho em saúde, de acordo com certos ideais consagrados pela medicina, hoje é confrontada, pois as fronteiras se tornaram móveis e dinâmicas. A suposta autonomia, tão defendida no antigo paradigma, a ponto de ser reafirmada constantemente nos discursos corporativos e documentos oficiais, não tem o mesmo significado de antes, uma vez que foi reinterpretada e se transformou profundamente no cenário que preconiza o trabalho colaborativo.

No presente estudo, os entrevistados se referem à equipe com qualificativos como "equipe complexa", que teria como característica crucial uma predisposição acentuada para cultivar a flexibilidade, o diálogo, o respeito às diferenças e o compartilhamento de açôes conjuntas.

Essa é uma equipe que tem a capacidade de se organizar e se reinventar todos os dias. Tem briga, tem discussão, nós nos confrontamos e nos reinventamos sempre (enfermeira).

Esta é uma ótima equipe, e uma equipe nunca pára. É cheia de problemas e nunca pára. Somos muitos e atravessamos todos os momentos de dificuldades. Estamos organizados como um grupo, como uma resposta às muitas perguntas (residente em Psiquiatria).

Os profissionais triestinos entrevistados defendem uma organização dinâmica e flexível, que articularia o trabalho em equipe como um processo em aberto e em constante mutação. Segundo essa concepção dialética, as contradiçóes devem ser expostas e colocadas claramente na mesa no decorrer da atuação profissional, para que as diferenças possam ser visibilizadas e confrontadas. A síntese produzida a partir do confronto de perspectivas distintas sobre o cuidar, por sua vez, pode ser o ponto de partida para novas teses e antíteses, que evoluem em uma crescente espiral dialética. Nessa vertente, a equipe não é algo que preexiste ao trabalho. Pelo contrário, é o trabalho que instaura e dá sentido à equipe. Evidentemente, há concepçôes teóricas que engendram e dão sustentação ao trabalho a ser desenvolvido, mas a necessidade de "reinventar" os pressupostos "todos os dias" aponta para uma rejeição dos esquemas prontos e cristalizados pela repetição reiterada na prática cotidiana. É necessário cultivar uma disposição renovada para lutar contra o instituído, isto é, aquilo que tende a se repetir automaticamente, perpetuando-se no curso do tempo, petrificado em estruturas esclerosadas (Pillon, Jora, \& Santos, 2011).
Investindo contra a suposta possibilidade de se encontrar uma estabilidade idealizada, um dos entrevistados (residente em Psiquiatria) opina que "uma equipe nunca pára”. Em seu entendimento, o fato de estarem "organizados como grupo" fortalece os profissionais e os motivam a enfrentar juntos os desafios que encontram pela frente, até que consigam amadurecer "uma resposta às muitas perguntas". Mas, no relato de uma das enfermeiras entrevistadas, ser equipe não implica em pensar de forma homogênea ("tem briga, tem discussão, nós nos confrontamos e nos reinventamos sempre"). Entende-se que a expressão "nós nos confrontamos", mais do que o atrito provocado pelo embate de diferenças individuais supostamente irreconciliáveis, alude a uma prontidáo para manter um saudável questionamento em relação às ideias preconcebidas, consagradas e sancionadas pela tradição.

Nesse cenário, a instabilidade é preferível à estabilidade, sendo esta última vista como reconfortante, porém perigosa, já que pode gerar conformismo com as estruturas estereotipadas que empobrecem o pensar. Desse modo, os relatos obtidos convergem em defesa da dimensão criativa e viva do trabalho em saúde mental, quando este serve de campo de tensionamento em vez de silenciamento das contradiçóes produzidas pelas práticas em saúde mental (Barros, Calmon, Santos, \& Rigobello, 2005; Oliveira-Pereira \& Santos, 2012).

Isso exige colocar em cheque os modos de organização do trabalho que não se submetem diuturnamente à reflexáo crítica. $\mathrm{O}$ profissional forjado pelo modo de atenção psicossocial deve ser permeável à crítica e praticante assíduo da autocrítica (Amarante, 2008; Rotelli, 2008). Não se trata, certamente, do modelo de profissional médico que a análise arguta de Schraiber (2008) se propóe a desvendar, quando a autora aponta que a maioria, embora expresse suas perplexidades, parece estar de fato capturada e totalmente submissa à lógica tecnológica e mercadológica. Como salienta Schraiber, as profundas transformaçóes operadas na organização das práticas em saúde nas últimas décadas estão a exigir uma reflexão permanente sobre açóes "especialísticas", papéis e relaçôes de poder reproduzidas no cotidiano profissional.

\section{CONSIDERAÇÓES FINAIS}

O presente estudo contempla a possibilidade de compreender a transformação da prática desenvolvida por equipes de saúde mental ao percorrer as narrativas de protagonistas de um processo sócio-histórico que encena uma transição paradigmática em saúde mental. 
Trieste é considerada o berço da atenção comunitária de base territorial em saúde mental e do trabalho teórico e prático de desinstitucionalização (Basaglia, 1997; Del Giudice, 1998; Mezzina, 2017, Rotelli, 2015).

É oportuno destacar que, neste estudo, os entrevistados não são tomados como expoentes de suas respectivas categorias profissionais. Pelo contrário, são profissionais que se reconhecem como operadores comuns de uma equipe, embora mantenham suas vozes individuais. Por conseguinte, os depoimentos contribuem para desvelar o processo mutante e mutável de organização do trabalho em equipe, com aguçado senso de laço cooperativo.

A possibilidade de conhecer "desde dentro" o trabalho de uma equipe de saúde mental de Trieste na atualidade suscita alguns pontos merecedores de reflexão. O primeiro poderia ser o pano de fundo para todos os outros: uma rede pública de serviços comunitários de atenção em saúde mental pode funcionar satisfatoriamente, se bem desenvolvida em termos quantitativos - quantidade de serviços tendo como base a densidade populacional da cidade, quantidade de profissionais alocados nas equipes dos serviços - como também em termos qualitativos - grau de articulação das ações desenvolvidas pelos operadores, construção de práticas colaborativas no cotidiano das equipes.

A construção de práticas inovadoras, que colocam a pessoa e sua rede de recursos no centro das açóes e intervençôes realizadas, está intimamente relacionada à qualidade da interlocução conquistada nas últimas décadas entre profissionais, usuários, famílias e o uso parcimonioso dos recursos disponíveis no território. É preciso, em primeiro lugar, um empenho para a superação de condutas especialísticas adotadas na equipe e pela equipe. Em segundo lugar, é necessário garantir a ampliação de espaços de discussão em diversos níveis: reuniôes de equipe, articulação com outros serviços sanitários, organizaçóes de familiares e outros atores sociais, de modo a preservar o princípio do cuidado de base comunitária.

Os relatos dos profissionais de saúde mental triestinos corroboram a efetividade do investimento contínuo na construção de serviços de base territorial, articulando planejamento e contratos de gestão na organização dos serviços substitutivos de saúde mental. Corroboram também o que aponta Mezzina (2014) ao notar que os serviços de saúde mental de Trieste se caracterizam pela ênfase na organizaçáo consistente em termos de valores e princípios relacionados às necessidades dos usuários, que se refletem em cada componente, e não na ênfase exagerada em protocolos e procedimentos padronizados. Assim, o modelo triestino pode ser descrito mais em termos de práticas e relaçóes de cuidado do que de técnicas e tratamentos, constituindo um sistema por inteiro, orientado pelo princípio de recovery no cuidado em saúde mental de base comunitária.

Além da organização das práticas desenvolvidas junto aos usuários, os achados do presente estudo indicam que organizar o trabalho de maneira que se produzam espaços de discussão e reflexão permanentes sobre as açôes cotidianas se mostra uma estratégia não só desejável, mas essencial à consolidação da atenção psicossocial. Esses espaços de discussão são fecundos quando permeáveis à crítica e participação coletiva. Para tanto esses dispositivos devem ser cultivados também como espaços de formaçáo continuada dos profissionais em serviço, acionando estratégias que permitam colocar em debate as diretrizes nacionais que balizam o trabalho em saúde mental, juntamente com os saberes e poderes que essas diretrizes engendram. A análise das concepçôes teórico-práticas que sustentam tais diretrizes deve abarcar as contradiçóes que elas mobilizam, em torno de valores como cidadania, protagonismo e inclusão social. Tais contradições devem ser lidas e entendidas como inerentes à complexidade própria ao cuidado, que opera em sinergia com a complexidade da pessoa inserida em seu universo psicossocial.

\section{REFERÊNCIAS}

Amarante, P. (1995). Revisitando os paradigmas do saber psiquiátrico: tecendo o percurso do movimento da Reforma Psiquiátrica. In: P. Amarante (Org.), Loucos pela vida: A trajetória da Reforma Psiquiátrica no Brasil (pp. 21-55). Rio de Janeiro: Panoramal ENSP.

Amarante, P. (2008). Cultura da formação: reflexóes para a inovação no campo da saúde mental. In: P. Amarante \& L. B. Cruz (Orgs.), Saúde mental, formação e crítica (pp. 65-80). Rio de Janeiro: Fiocruz.

Amarante, P. (2011). Saúde mental e atenção psicossocial. Rio de Janeiro: Fiocruz.

Basaglia, F. (Org.) (1997). Che cos’è la psichiatria? Milano: Baldini \& Castoldi.

Barros, M. L., Calmon, T. F., Santos, M. A., \& Rigobello, L. X. (2005). Uma experiência de grupo operativo em um centro de atenção psicossocial: construindo novas possibilidades. In: M. A. Santos, C. P. Simon, \& L. L. Melo-Silva (Orgs.), Formação 
em Psicologia: Processos clínicos (pp. 235-253). São Paulo: Vetor.

Bogdan, R., \& Biklen, S. (1994). Investigação qualitativa em educação. Portugal: Porto.

Braun, V., \& Clarke, V. (2006). Using thematic analysis in psychology. Qualitative Research in Psychology, 3(2), 77-101.

Campos-Brustelo, T. N. C., Bravo, F. F., \& Santos, M. A. (2010). Contando e encantando histórias de vida em um centro de atenção psicossocial. SMAD: Revista Eletrônica Saúde Mental, Álcoole Drogas, 6(1), 1-11. Recuperado de http://pepsic.bvsalud.org/pdf/ smad/v4n2/v4n2a08.pdf

Costa-Rosa, A. (2000). O modo psicossocial: um paradigma das práticas substitutivas ao modo asilar. In: P. Amarante (Org.), Ensaios: Subjetividade, saúde mental e sociedade (pp. 141-168). Rio de Janeiro: Fiocruz.

Costa-Rosa, A. (2013). Atenção Psicossocial além da Reforma Psiquiátrica: Contribuição a uma clínica crítica dos processos de subjetivação na saúde coletiva. São Paulo: Unesp.

Del Giudice, G. (1998). La riforma psichiatrica in Italia. Recuperado de http://www.triestesalutementale. it/letteratura/testi/8rifpsi.htm

Fiorati, R. C., \& Saeki, T. (2013). The prevalence of medical/ clinical technology over psychosocial care actions in outpatient mental health services. Ciência \& Saúde Coletiva, 18(10), 2957-2963.

Foucault, M. (2000). O nascimento do hospital. In: Microfísica do poder (R. Machado, Trad.) (pp. 99-112). Rio de Janeiro: Graal.

Kantorski, L. P. (2001). A Reforma Psiquiátrica: um estudo parcial acerca da produção científica. Revista Eletrônica de Enfermagem, 3(2). Recuperado de https://revistas.ufg.br/fen/article/view/721/781

Machado, V. C., \& Santos, M. A. (2012). O apoio familiar na perspectiva do paciente em reinternação psiquiátrica: um estudo qualitativo. Interface: Comunicação, Saúde, Educação 16(42), 793-806.

Machado, V., \& Santos, M. A. (2013a). O tratamento extra-hospitalar em saúde mental na perspectiva do paciente reinternado. Psicologia em Estudo (Maringá), 18(4), 2013, 701-712.

Machado, V., \& Santos, M. A. (2013b). Vivências familiares de pacientes com reinternação psiquiátrica. Aletheia, 40, 111-119.

Machado, V. C., Leonidas, C., \& Santos, M. A. (2012). Psychiatric readmission: an integrative review of the literature. International Nursing Review, 59(4), 447-457.
Mângia, E. F. (2009). Formação e educação permanente para produzir boas práticas em saúde mental. Revista de Terapia Ocupacional USP, 20(2), i-ii.

Mari, J. J., Bressan, R. A., Almeida-Filho, N., Gerolin, J., Sharan, P., \& Saxena, S. (2006). Mental health research in Brazil: policies, infrastructure, financing and human resources. Revista de Saúde Pública, 40(1), 161-169.

Mezzina, R. (2005). Paradigm shift in psychiatry: processes and outcomes. In: S. Ramon \& J. E. Williams (Eds.), Mental health at the crossroads: The promise of the psychosocial approach (pp. 81-93). London: Ashgate.

Mezzina, R. (2014). Community mental health care in Trieste and beyond: an "open door e no restraint" system of care for recovery and citizenship. Journal of Nervous and Mental Disease, 202(6), 440-445.

Mezzina, R. (2017). Per una discussione critica sul tema della "recovery" in Italia e in Europa. Cadernos Brasileiros de Saúde Mental, 9(21), 161-181.

Ministério da Saúde (2005). Secretaria de Atenção à Saúde. DAPE. Coordenação Geral de Saúde Mental. Reforma psiquiátrica e política de saúde mental no Brasil. Brasília: Autor. Recuperado de http://fgg. rio.rj.gov.br/publique/ media/Relatorio_20anos_ Caracas.pdf

Ministério da Saúde (2015) Secretaria de Atenção à Saúde. Departamento de Açóes Programáticas Estratégicas. Coordenação Geral de Saúde Mental, Álcool e Outras Drogas. Saúde mental em dados 12. Brasília, DF: Autor.

Oliveira-Pereira, T. T. S., \& Santos, M. A. (2012). Care group for mental health staff: a professional development strategy. Revista Brasileira de Crescimento e Desenvolvimento Humano, 22(1), 68-72.

Oliveira-Pereira, T. T. S., Barros, N. S., \& Augusto, M. C. N. A. (2011). O cuidado em saúde: o paradigma biopsicossocial e a subjetividade em foco. Mental (Barbacena), 9(17), 523-536.

Pegoraro, R. F. (2007). Receber e prover cuidados: a trajetória de uma mulher em sofrimento psíquico. Tese de Doutorado, Faculdade de Filosofia, Ciências e Letras de Ribeirão Preto, Universidade de São Paulo, Ribeirão Preto, SP.

Pillon, S. C., Jora, N. P., \& Santos, M. A. (2011). O papel da equipe interdisciplinar na dependência química. In: A. Diehl, D. C. Cordeiro, \& R. Laranjeira (Orgs.), Dependência química: prevenção, tratamento e políticas públicas (pp. 453-460). Porto Alegre, RS: Artmed. 
Romeo, J. A. L. (2010). El trabajo en equipo interdisciplinar en salud mental: mito, deseo o realidad? Informaciones Psiquiátricas, 202(4), 385-390.

Rotelli, F. (1990). Desinstitucionalização: uma outra via. In: F. Nicácio (Org.), Desinstitucionalização (pp. 17-59). São Paulo: Hucitec.

Rotelli, F. (2008). Formação e construção de novas instituiçôes em saúde mental. In: P. Amarante \& L. B. Cruz (Orgs.), Saúde mental, formação e crítica (pp. 37-50). Rio de Janeiro: Fiocruz.

Rotelli, F. (2015). L'istituizione inventata: Almanacco Trieste 1971-2010. Merano: Alpha Beta Verlag.

Saraceno, B. (2014). Discorso globale, sofferenze locali: analisi critica del movimento di salute mentale globale. Milano: Il Saggiatore.

Servizio Sanitario Regionale. Azienda per i servizi sanitari N.1 Triestina (2012). Atto aziendale. Recuperado de http://www.ass1.sanita.fvg.it/opencms/export/sites/ass1/it/ chi_siamo/_docs/atto_aziendale_391_2012.pdf

Schraiber, L. B. (1993). O médico e seu trabalho: limites da liberdade pessoal. São Paulo: Hucitec.

Schraiber, L. B. (2008). O médico e suas interaçôes: a crise dos vínculos de confiança. São Paulo: Hucitec.

Turato, E. G. (2003). Tratado da metodologia da pesquisa clinico-qualitativa: construçâo teórico-epistemológica: discussão comparada e aplicaçâo nas áreas da saúde e humanas. Petrópolis, RJ: Vozes.

Vasconcellos, V. C. (2010). Trabalho em equipe na saúde mental: o desafio interdisciplinar em um CAPS.
Revista Eletrônica Saúde Mental, Álcool e Drogas, 6(1), 1-16.

World Health Organization (2005). Mental health policy and service guidance package: human resources and training in mental health. Genebra: Author.

World Health Organization (2010). Collaborating centers designation form. Recuperado de http://www. deistituzionalizzazione-trieste.it/oms/Oms/OMS_ designation_form.pdf

Yasui, S. (2010). Rupturas e encontros: desafios da reforma psiquiátrica brasileira. Rio de Janeiro: Fiocruz.

Yasui, S. (2011). Conhecendo as origens da Reforma Psiquiátrica brasileira: as experiências francesa e italiana. História, Ciências, Saúde: Manguinhos, 18(2), 585-589.

Yasui, S., \& Costa-Rosa, A. (2008). A Estratégia Atenção Psicossocial: desafio na prática dos novos dispositivos de Saúde Mental. Saúde em Debate,32(78/79/80), 27-37.

\section{Endereço para correspondência:}

Thaís Thomé S. S. Oliveira

Via Weiss, n.5 - Parco San Giovanni

CAP: 34127 - Trieste/TS - Italia

E-mail: thasenne@gmail.com

Recebido em 05/03/2017

Aceito em 05/06/2017 